Supplement of Biogeosciences, 16, 3583-3603, 2019

https://doi.org/10.5194/bg-16-3583-2019-supplement

(C) Author(s) 2019. This work is distributed under

the Creative Commons Attribution 4.0 License.

(c) (1)

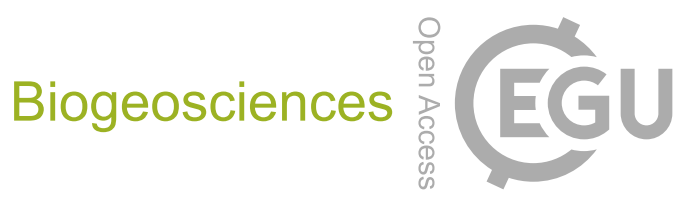

Supplement of

\title{
Sensitivity of ocean biogeochemistry to the iron supply from the Antarctic Ice Sheet explored with a biogeochemical model
}

Renaud Person et al.

Correspondence to: Renaud Person (renaud.person@locean-ipsl.upmc.fr)

The copyright of individual parts of the supplement might differ from the CC BY 4.0 License. 

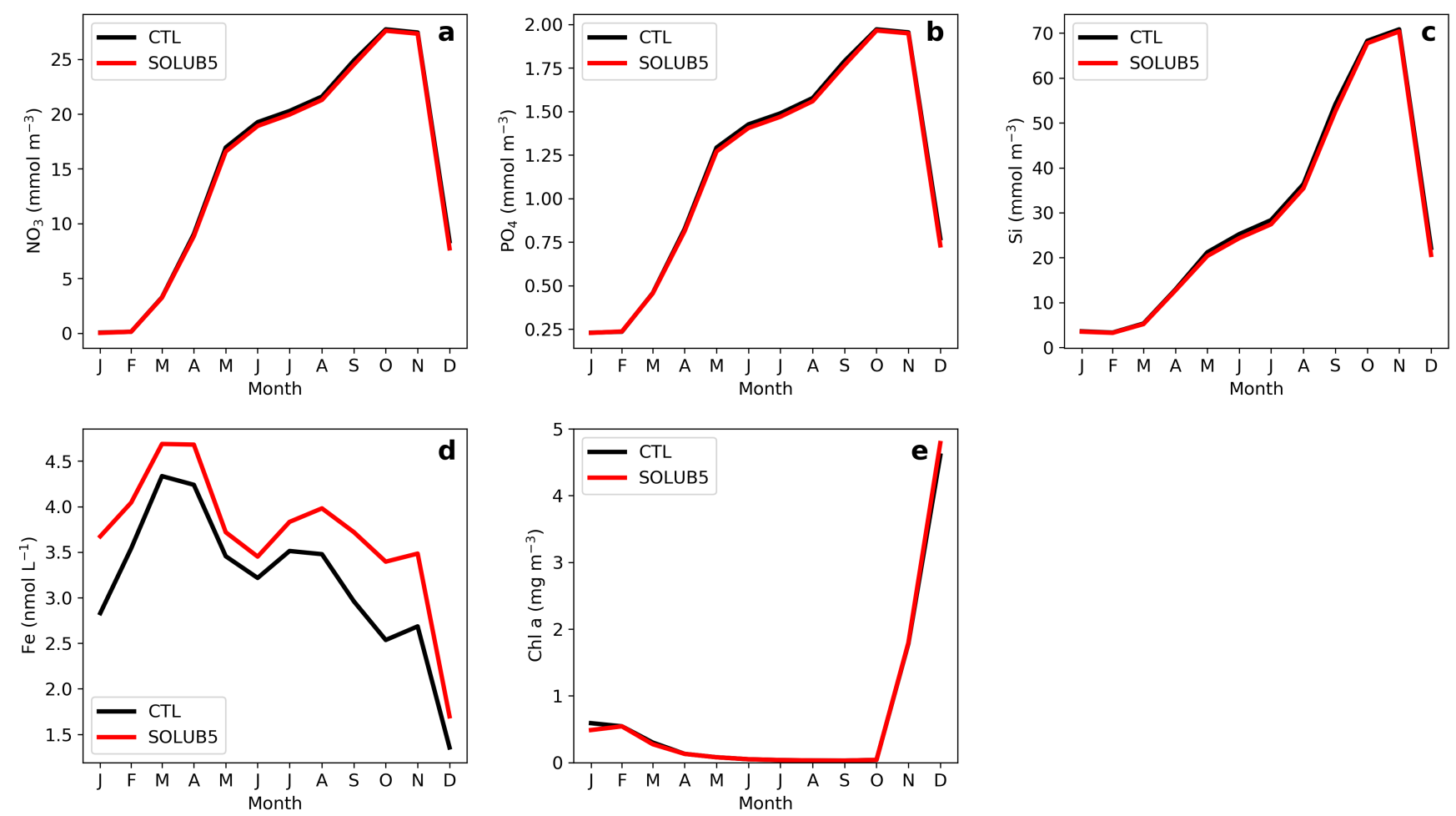

Figure S1. Seasonal cycles of surface (a) $\mathrm{NO}_{3}$, (b) $\mathrm{PO}_{4}$, (c) $\mathrm{Si}$, (d) Fe, and (e) chlorophyll concentrations at a near shore station in the Amundsen Sea $\left(106^{\circ} \mathrm{W}, 75^{\circ} \mathrm{S}\right)$ in the CTL experiment (black) and the SOLUB5 experiment (red). 

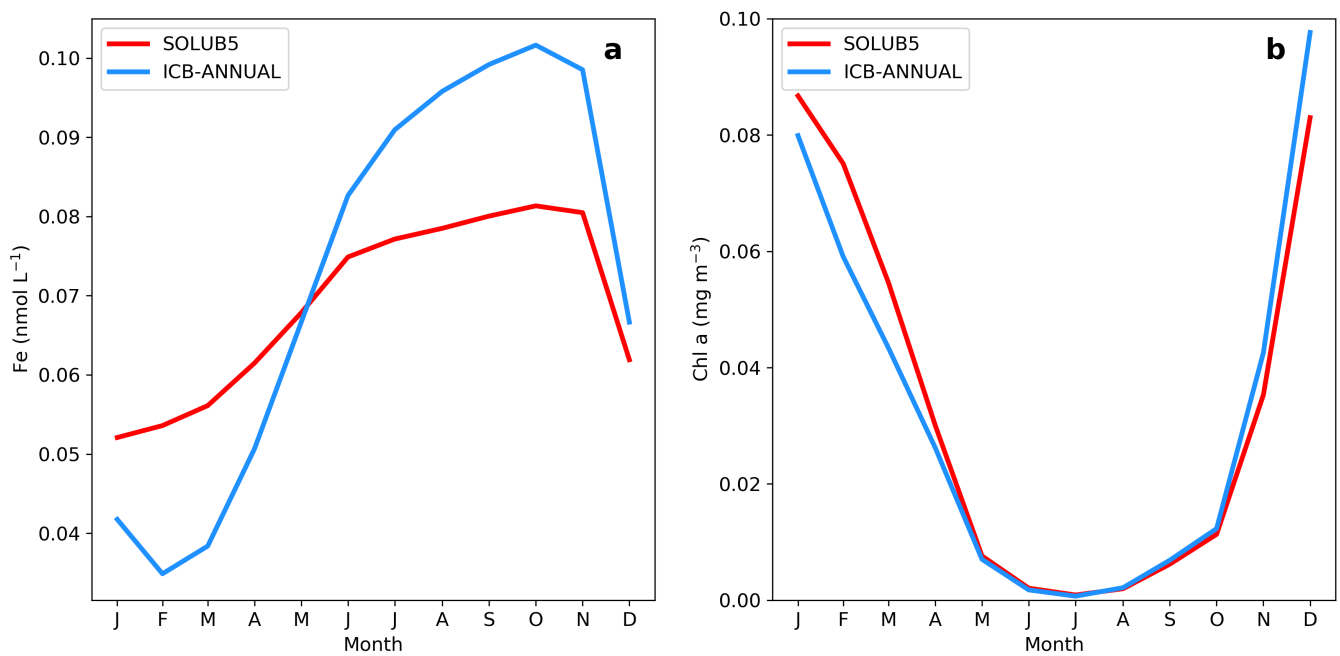

Figure S2. Seasonal cycles of anomalies of surface (a) Fe and (b) chlorophyll concentrations in the SOLUB5 experiment (red) and in the ICB-ANNUAL experiment (blue) relative to the CTL experiment over the $\mathrm{SO}$, south of $50^{\circ} \mathrm{S}$. 
Table S1. Statistical Model-Data comparison for annual Fe concentrations in the upper $200 \mathrm{~m}$ in the Southern Ocean, south of $50^{\circ} \mathrm{S}$, between observations (Tagliabue et al., 2012) and SOLUB1, SOLUB5, SOLUB10, ICB-SURF, ICB-ML, and ICB-ANNUAL experiments. R, AE, RMSE, STD, RI, and MEF are, respectively, the correlation coefficient, the average error, the root mean square error, the normalized standard deviation, the reliability index, and the modeling efficiency.

\begin{tabular}{lccccccc}
\hline Experiments & $\begin{array}{c}\text { Mean } \\
\left(\mathrm{nmol} \mathrm{L^{-1 }}\right)\end{array}$ & $\mathrm{R}$ & $\begin{array}{c}\text { AE } \\
\left.(\mathrm{nmol} \mathrm{L})^{-1}\right)\end{array}$ & RMSE & STD & RI & MEF \\
\hline OBS (n=282) & 0.39 & & & & & & \\
CTL & 0.32 & 0.30 & -0.07 & 0.67 & 0.35 & 2.74 & 0.07 \\
SOLUB1 & 0.33 & 0.30 & -0.06 & 0.66 & 0.38 & 2.76 & 0.08 \\
SOLUB5 & 0.37 & 0.30 & -0.02 & 0.67 & 0.48 & 2.82 & 0.05 \\
SOLUB10 & 0.41 & 0.29 & 0.02 & 0.70 & 0.60 & 2.91 & -0.01 \\
ICB-SURF & 0.36 & 0.31 & -0.03 & 0.67 & 0.47 & 2.80 & 0.07 \\
ICB-ML & 0.34 & 0.28 & -0.05 & 0.67 & 0.41 & 2.77 & 0.06 \\
ICB-ANNUAL & 0.37 & 0.29 & -0.02 & 0.68 & 0.47 & 2.81 & 0.05 \\
\hline
\end{tabular}


Table S2. Statistical Model-Data comparison for surface chlorophyll concentrations in summer (DJF) in the Southern Ocean, south of $50^{\circ} \mathrm{S}$, between satellite estimates (Modis-Aqua, Johnson et al. (2013)) and SOLUB1, SOLUB5, SOLUB10, ICB-SURF, ICB-ML, and ICBANNUAL experiments. R, AE, RMSE, STD, RI, and MEF are, respectively, the correlation coefficient, the average error, the root mean square error, the normalized standard deviation, the reliability index, and the modeling efficiency.

\begin{tabular}{lccccccc}
\hline Experiments & $\begin{array}{c}\text { Mean } \\
\left(\mathrm{mg} \mathrm{Chl} \mathrm{m}^{-3}\right)\end{array}$ & $\mathrm{R}$ & $\begin{array}{c}\text { AE } \\
\left(\mathrm{mg} \mathrm{Chl} \mathrm{m}^{-3}\right)\end{array}$ & RMSE & STD & RI & MEF \\
\hline OBS (n=15,533) & 0.55 & & & & & & \\
CTL & 0.43 & 0.50 & -0.13 & 0.42 & 0.70 & 1.8 & 0.14 \\
SOLUB1 & 0.43 & 0.51 & -0.12 & 0.42 & 0.72 & 1.8 & 0.15 \\
SOLUB5 & 0.46 & 0.52 & -0.10 & 0.42 & 0.78 & 1.8 & 0.16 \\
SOLUB10 & 0.48 & 0.53 & -0.07 & 0.42 & 0.82 & 1.7 & 0.16 \\
ICB-SURF & 0.48 & 0.52 & -0.07 & 0.43 & 0.86 & 1.75 & 0.12 \\
ICB-ML & 0.44 & 0.51 & -0.11 & 0.42 & 0.75 & 1.8 & 0.15 \\
ICB-ANNUAL & 0.45 & 0.52 & -0.10 & 0.41 & 0.75 & 1.75 & 0.17 \\
\hline
\end{tabular}




\section{References}

Johnson, R., Strutton, P. G., Wright, S. W., McMinn, A., and Meiners, K. M.: Three improved satellite chlorophyll algorithms for the Southern Ocean, Journal of Geophysical Research: Oceans, 118, 3694-3703, https://doi.org/10.1002/jgrc.20270, 2013.

Tagliabue, A., Mtshali, T., Aumont, O., Bowie, A. R., Klunder, M. B., Roychoudhury, A. N., and Swart, S.: A global compilation of dissolved iron measurements: focus on distributions and processes in the Southern Ocean, Biogeosciences, 9, 2333-2349, https://doi.org/10.5194/bg-9-2333-2012, 2012. 